\title{
EDITORIAL
}

\section{Guiding ventilation with transpulmonary pressure}

\author{
Takeshi Yoshida', Domenico Luca Grieco ${ }^{2}$ and Laurent Brochard ${ }^{3,4^{*}}$
}

(C) 2018 Springer-Verlag GmbH Germany, part of Springer Nature

\begin{abstract}
Introduction
Improving the short-term and long-term outcome of mechanically ventilated patients remains a difficult task for the intensivist. Randomized controlled trials repeatedly failed to bring evidence supporting new approaches. In this regard, a better characterization of the patient in order to individualize therapy is strongly advocated. The measurement of transpulmonary pressure $\left(P_{\mathrm{L}}\right)$ is now possible in our ICUs thanks to a good knowledge about the oesophageal pressure $\left(P_{\mathrm{es}}\right)$ technique and is and will be facilitated by the possibility of using additional pressure ports on recent modern mechanical ventilators.
\end{abstract}

\section{What transpulmonary pressure exactly measures}

In the 1950s, several observations reported good correlations between changes in pleural pressure $\left(P_{\mathrm{pl}}\right)$, directly measured in the pleural space, and changes in $P_{\text {es }}$. After refinements of the technique and use of convenient catheters equipped with oesophageal balloons, this technique has been introduced in the research field and has allowed major advances in understanding respiratory system pathophysiology. In patients with spontaneous breathing, the relative changes in $P_{\text {es }}$ and $P_{\mathrm{L}}$ have been repeatedly used to quantify the work of breathing using the Campbell diagram or by calculating the pressure time product of the respiratory muscles, considered as the best indicator of the energy consumption of the respiratory muscles.

As for the absolute values of $P_{\mathrm{es}}$, in line with a classical study [1], recent experiments in pigs and in human cadavers showed that the absolute value of the $P_{\mathrm{es}}$ is highly reliable, provided that a proper technique is used

*Correspondence. BrochardL@smh.ca

${ }^{3}$ Keenan Research Centre, Li Ka Shing Knowledge Institute, St. Michael's Hospital, 30 Bond St, Toronto, ON M5B 1W8, Canada

Full author information is available at the end of the article
[2]. There is, however, no unique value of $P_{\mathrm{pp}}$, and a gradient of pressure exists between the upper, anterior part of the pleural space when the patient is lying supine, also referred to as the 'non-dependent' pleural regions, vs. the dorsal, posterior part of the pleural space, also referred to as the 'dependent' pleural regions. This gradient explains the distribution of densities in the lung and may reach values around $10 \mathrm{cmH}_{2} \mathrm{O}$ [1]. Because the oesophagus is approximately situated at mid chest, the value read by the oesophageal catheter therefore reflects the value related to the anatomic position of the oesophagus in the thoracic cavity.

\section{How transpulmonary pressure could guide PEEP: absolute value of oesophageal pressure}

The lung collapse characteristically aggregates in dependent lung along a gravitational direction and dependent collapsed lung contributes to intrapulmonary shunting and lowers oxygenation. Positive end-expiratory pressure (PEEP) theoretically maintains positive lung distending transpulmonary pressure at end-expiration, i.e. PEEP minus $P_{\mathrm{p}}$, leading to minimizing dependent collapse. However, $P_{\mathrm{pl}}$ is variable and unpredictable without specific monitoring as a result of abnormal chest wall mechanics and/or increased oedema, so that it is uncertain if PEEP can maintain positive $P_{\mathrm{L}}$ without knowing $P_{\mathrm{pl}}$ (for instance in obese patients or patients with ARDS [3]). Oesophageal manometry is a non-invasive technique to measure $P_{\mathrm{pl}}$ and thus estimate the lung distending transpulmonary pressure [4]. Preliminary validation of $P_{\mathrm{es}}$ to optimize PEEP is encouraging [5]. A clinical trial showed that a ventilatory strategy using $P_{\mathrm{es}}-$ a surrogate

\section{里 Springer}


of $P_{\mathrm{pl}}$-at end-expiration to maintain a positive value of $P_{\mathrm{L}}$ had physiological benefits, i.e. better oxygenation and better respiratory system compliance in patients with ARDS [5]. Our recent validation study (pigs and human cadavers) of $P_{\mathrm{es}}$ using direct $P_{\mathrm{pl}}$ sensor revealed that measured $P_{\text {es }}$ accurately reflects local $P_{\mathrm{pl}}$ in the mid to dependent lung, adjacent to the oesophageal balloon [2]. Since lung collapse usually predominates in dependent lung in ARDS, setting PEEP using expiratory $P_{\text {es }}$ to prevent dependent atelectasis makes sense (Fig. 1). Ideally, however, this measurement should be combined with an assessment of lung recruitability.

\section{How transpulmonary pressure could help to avoid overdistension: calculated value based on the elastance ratio}

Ventilator-induced lung injury in ARDS is known to occur in the ventilated, non-dependent lung regions, termed the 'baby' lung [6]. Thus, assessing the risk of local overdistension, i.e. local inspiratory lung distending transpulmonary pressure in the ventilated, non-dependent, lung region, is essential to minimize ventilatorinduced lung injury. The direct $P_{\mathrm{L}}$ obtained using the absolute value of $P_{\text {es }}$ reflects the value at mid chest and so does not assess the risk of the non-dependent lung.

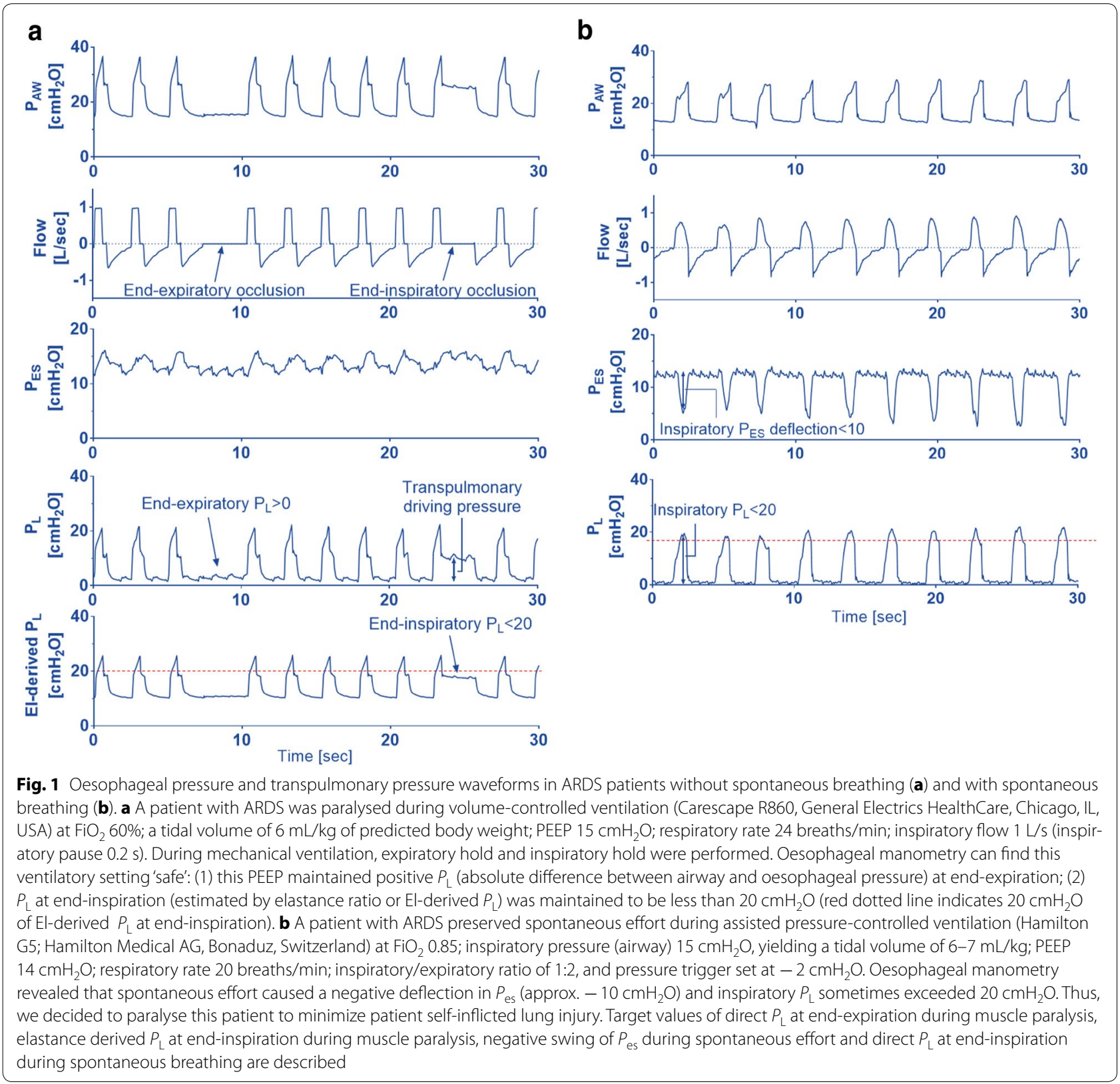


Fortunately, our study [2] showed that $P_{\mathrm{L}}$ at end-inspiration in the non-dependent lung, i.e. the most at-risk region, can be reasonably estimated by the following calculation:

[Plateau pressure

$$
\times(\text { Lung elastance/Respiratory system elastance })] \text {. }
$$

Elastance ratio of lung to respiratory system is calculated as the quotient between elastance of the lung and elastance of the respiratory system. Our recent validation study (pigs and human cadavers) of $P_{\mathrm{es}}$ using a direct $P_{\mathrm{pl}}$ sensor revealed that $P_{\mathrm{L}}$ at end-inspiration (estimated by elastance ratio) reflected the local distending pressure in non-dependent 'baby' lung well [2]. This region is the most susceptible to overdistension at end-inspiration, and its local distending pressure may be a more sensitive marker of risk from barotrauma than conventional 'global' parameters that fail to take account of regional differences or chest wall properties. We do not know enough about the safe limits for this pressure, but keeping it below $22-25 \mathrm{cmH}_{2} \mathrm{O}$ (known as the upper limit of physiological range) appears wise to prevent regional overdistension [4] (Fig. 1).

Respiratory system compliance reflects the aerated lung size, and the airway driving pressure (ratio of tidal volume to respiratory system compliance, i.e. $\frac{\text { Tidal volume }}{[\text { Tidal volume/Airway driving pressure }]}$ ) represents the

mechanical distortion caused by tidal volume in the aerated lung (i.e. dynamic strain). It is possible that the lung driving pressure (ratio of tidal volume to lung compliance, i.e. $\frac{\text { Tidal volume }}{[\text { Tidal volume/Lung driving pressure }]}$ ) could be a more precise index [7], especially when chest wall mechanics is significantly impaired and could help to titrate tidal volume, but further validation will be needed.

\section{How transpulmonary pressure could guide spontaneous breathing activity}

Spontaneous breathing activity can offer protective effects to the lung and diaphragm in patients with ARDS, i.e. better gas exchange and less diaphragm atrophy [8-10]. However, it is important to note that this protective role of spontaneous effort has been shown in less severe ARDS and with mild spontaneous effort. Recent studies indicate that spontaneous effort may injure and/or worsen already injured lung and diaphragm in severe ARDS, especially when spontaneous effort is vigorous [8-12]. First, vigorous effort may present injuriously high $P_{\mathrm{L}}$ (static and/or dynamic) by lowering $P_{\mathrm{pl}}$ despite a limitation of plateau pressure, causing patient self-inflicted lung injury [13].
Second, vigorous spontaneous effort is associated with increasing diaphragm thickness (potentially diaphragm injury), which is associated with prolonged ventilation $[9,10]$. Third, vigorous effort can cause lung oedema by increasing transmural vascular pressure (calculated as intravascular pressure minus $P_{\mathrm{pl}}$ ), i.e. the net pressure to distend the intrathoracic vessels. This harmful phenomenon is well described in patients with ARDS who preserved vigorous effort during volume-controlled low tidal ventilation [14]. Thus, it is important to monitor spontaneous effort activity (reflected by negative dynamic deflection of $P_{\mathrm{es}}$ ) and maintain $P_{\mathrm{L}}$ within a safe range, to protect not only the lung but also the diaphragm in patients with ARDS (Fig. 1).

\section{Conclusion}

Ventilator-induced lung injury and patient self-inflicted lung injury have the potential to generate lung and systemic inflammation and cause organ damage or death. An individualized monitoring using $P_{\mathrm{es}}$, i.e. the absolute value at end-expiration, the calculated end-inspiratory value based on the elastance ratio and the negative swings during spontaneous breathing, might allow a more precise titration of ventilatory settings for a safe and efficient ventilation. This should help to manage the complex interactions of spontaneous breathing and mechanical insufflation. The next generation of randomized controlled trials might incorporate such tools and implementation in clinical practice seems justified today.

\section{Author details \\ ${ }^{1}$ The Department of Anesthesiology and Intensive Care Medicine, Osaka Uni- versity Graduate School of Medicine, Suita, Japan. ${ }^{2}$ Department of Anesthe- siology and Intensive Care Medicine, Catholic University of the Sacred Heart, Fondazione Policlinico Universitario A. Gemelli IRCCS, Rome, Italy. ${ }^{3}$ Keenan Research Centre, Li Ka Shing Knowledge Institute, St. Michael's Hospital, 30 Bond St, Toronto, ON M5B 1W8, Canada. ${ }^{4}$ Interdepartmental Division of Criti- cal Care Medicine, University of Toronto, Toronto, Canada.}

Compliance with ethical standards

\section{Conflicts of interest}

TY has a patent on a CNAP device. DLG is supported by SIAARTI/Merck Sharp \& Dohme and ESICM (2017 Bernhard Dräger Award for Advanced Treatment of Acute Respiratory Failure), has received payments for travel expenses by Maquet, Getinge and Air Liquide and discloses a research grant by General Electrics Healthcare. LB's laboratory has received grants or equipment from Covidien-Medtronic, Fisher Paykel, Air Liquide, Philips, General Electric.

Received: 26 October 2018 Accepted: 26 November 2018 Published online: 30 November 2018

\footnotetext{
References

1. Pelosi P, Goldner M, McKibben A, Adams A, Eccher G, Caironi P, Losappio S, Gattinoni L, Marini JJ (2001) Recruitment and derecruitment during
} 
acute respiratory failure: an experimental study. Am J Respir Crit Care Med 164:122-130

2. Yoshida T, Amato MBP, Grieco DL, Chen L, Lima CAS, Roldan R, Morais CCA, Gomes S, Costa ELV, Cardoso PFG, Charbonney E, Richard JM, Brochard L, Kavanagh BP (2018) Esophageal manometry and regional transpulmonary pressure in lung injury. Am J Respir Crit Care Med 197:1018-1026

3. Fumagalli J, Berra L, Zhang C, Pirrone M, Santiago RRS, Gomes S, Magni F, Dos Santos GAB, Bennett D, Torsani V, Fisher D, Morais C, Amato MBP, Kacmarek RM (2017) Transpulmonary pressure describes lung morphology during decremental positive end-expiratory pressure trials in obesity. Crit Care Med 45:1374-1381

4. Mauri T, Yoshida T, Bellani G, Goligher EC, Carteaux G, Rittayamai N, Mojoli F, Chiumello D, Piquilloud L, Grasso S, Jubran A, Laghi F, Magder S, Pesenti A, Loring S, Gattinoni L, Talmor D, Blanch L, Amato M, Chen L, Brochard L, Mancebo J, PLeUral pressure working Group (PLUG-Acute Respiratory Failure section of the European Society of Intensive Care Medicine) (2016) Esophageal and transpulmonary pressure in the clinical setting: meaning, usefulness and perspectives. Intensive Care Med 42:1360-1373

5. Talmor D, Sarge T, Malhotra A, O'Donnell CR, Ritz R, Lisbon A, Novack V, Loring SH (2008) Mechanical ventilation guided by esophageal pressure in acute lung injury. N Engl J Med 359:2095-2104

6. Gattinoni L, Marini JJ, Pesenti A, Quintel M, Mancebo J, Brochard L (2016) The "baby lung" became an adult. Intensive Care Med 42:663-673

7. Baedorf Kassis E, Loring SH, Talmor D (2016) Mortality and pulmonary mechanics in relation to respiratory system and transpulmonary driving pressures in ARDS. Intensive Care Med 42:1206-1213
8. Yoshida T, Uchiyama A, Matsuura N, Mashimo T, Fujino Y (2013) The comparison of spontaneous breathing and muscle paralysis in two different severities of experimental lung injury. Crit Care Med 41:536-545

9. Goligher EC, Fan E, Herridge MS, Murray A, Vorona S, Brace D, Rittayama N, Lanys A, Tomlinson G, Singh JM, Bolz SS, Rubenfeld GD, Kavanagh BP Brochard LJ, Ferguson ND (2015) Evolution of diaphragm thickness during mechanical ventilation. Impact of inspiratory effort. Am J Respir Crit Care Med 192:1080-1088

10. Goligher EC, Dres M, Fan E, Rubenfeld GD, Scales DC, Herridge MS, Vorona S, Sklar MC, Rittayamai N, Lanys A, Murray A, Brace D, Urrea C, Reid WD, Tomlinson G, Slutsky AS, Kavanagh BP, Brochard LJ, Ferguson ND (2018) Mechanical ventilation-induced diaphragm atrophy strongly impacts clinical outcomes. Am J Respir Crit Care Med 197:204-213

11. Lalgudi Ganesan S, Jayashree M, Chandra Singhi S, Bansal A (2018) Airway pressure release ventilation in pediatric acute respiratory distress syndrome. A randomized controlled trial. Am J Respir Crit Care Med 198:1199-1207

12. Morais CCA, Koyama Y, Yoshida T, Plens GM, Gomes S, Lima CAS, Ramos OPS, Pereira SM, Kawaguchi N, Yamamoto H, Uchiyama A, Borges JB, Vidal Melo MF, Tucci MR, Amato MBP, Kavanagh BP, Costa ELV, Fujino Y (2018) High positive end-expiratory pressure renders spontaneous effort noninjurious. Am J Respir Crit Care Med 197:1285-1296

13. Brochard L, Slutsky A, Pesenti A (2017) Mechanical ventilation to minimize progression of lung injury in acute respiratory failure. Am J Respir Crit Care Med 195:438-442

14. Kallet RH, Alonso JA, Luce JM, Matthay MA (1999) Exacerbation of acute pulmonary edema during assisted mechanical ventilation using a lowtidal volume, lung-protective ventilator strategy. Chest 116:1826-1832 